MINER, Horace

1953 The primitive city of Timbuctoo. Princeton.

MoLIIEN, G.

1820 Travels in the interior of Africa to the sources of the Senegal and Gambia, ed. T. E. Bowdich. London. Excerpts provided by D. P. Gamble.

MOORE, Francis

1738 Travels into the inland parts of Africa. London.

PARX, MUNGo

1799 Travels in the interior districts of Africa. Reissued in Everyman's Library (1907).

SAUUGNIER, $M$.

1791 Relations de plusieurs voyages a la côte d'Afrique, a Maroc, au Senegal, a Gorée, a Galam, etc. Paris.

Select Commttee on West Coast of Africa

1842 Quotation provided by D. P. Gamble.

Thmendus, G.

1920 Primitives Geld. Archiv für Anthropologie, n.s. 18:1-33.

THURNWALD, RICHARD

1932 Economics in primitive communities. London.

WYNDHAM, H. A.

1935 The Atlantic and slavery. London.

\section{Avunculocal Residence on Losap}

\section{J. L. FISCHER}

Harvard University

HE purpose of this paper is to report a contemporary instance of avuncu1 local residence in Micronesia, on the island of Losap, Truk District, and to discuss possible reasons for the presence of this trait on Losap, surrounded as it is by matrilocal societies to the north and south.

Losap Atoll is located about fifty miles southeast of Truk Lagoon in the east central Caroline Islands. The nearest land is the single coral island of Nama, about twelve miles to the northeast. Both Losap and Nama lie along a route between Truk and the Mortlock (also known as $\mathrm{Ku}$ or Nomoi) Islands, a group of atolls roughly 100 to 150 miles southeast of Truk.

Culturally, too, Losap is in many ways intermediate between Truk and the Mortlocks. At the same time, it possesses a number of special cultural characteristics not found in the adjoining islands. The local dialect, for instance, retains an initial $k$ in certain words which has been lost in both Trukese and Mortlockese (e.g., the first person plural exclusive absolute pronoun is äam in Trukese, ämem in Mortlockese, and kämem in the Losap dialect).

The Losap people claim that in aboriginal times the chiefs of Losap Island held dominion over the inhabitants of Pis Island, at the other end of the lagoon, and over the nearby island of Nama as well. Foreigners have tended to assume that all three communities were closely related culturally, because of the geographical proximity and perhaps also because of the political relationship. However, the natives themselves claim that the people of Nama are more closely related to those of Kutu in the Mortlocks than to those of nearby Losap. They explain that in prehistoric times a typhoon nearly annihilated the true inhabitants of Nama, who were then related to the Losap people, and that settlers from Kutu repopulated the island. The speech and social organization of the Nama people, as far as I am familiar with them, are distinct from those of Losap and thus bear out this story, as does the fact that the Nama and Kutu people even today exchange gifts and visit back and forth with special frequency. One would expect that any typhoon devastating Nama would do considerable damage to Losap, but Losap proper is especially well protected from storms from any direction, as coral islands go, since it is on the inner side of a particularly broad stretch of atoll reef and has another island between it and the sea side. One would expect, therefore, that the Losap population would survive a typhoon with considerably fewer casualties.

Pis Island, the other inhabited island in Losap Lagoon, is culturally similar to Losap. Although it is now officially a separate municipality under the American administration of the Trust Territory, the people and officials have continued to look for leadership to the parent island of Losap proper. It is no doubt significant that the name "Pis" is a term widely applied throughout the Greater Truk area to small or uninbabited satellite islands. 
One of the most striking of the unique characteristics of Losap society is the pattern of avunculocal residence, the subject of this paper. In $1950 \mathrm{I}$ had the patter to make an extensive survey of marital residence on all the major island groups of Greater Truk (Truk proper, the Halls, Namonuito, Puluwat and nearby islands, the Mortlocks, and Losap and Nama). This survey showed that avunculocal residence is practically nonexistent elsewhere in Truk District, while on Losap it is the dominant form. A census showed that Irap 53 couples were living in avunculocal residence, 22 matrilocal, 16 on 1 unknown to the informants. The contrast with the nearby island of Nama is especially striking, for Nama proved to be the most strongly matrilocal island in the whole district (113 matrilocal, 3 patrilocal, 1 neolocal, and 1 unknown to informant).

The survey of residence on Losap was conducted by asking several natives of the island, visiting Truk, to tell me who was living in each house on the island as of the date they had left, what were the relationships of each adult, and owned the land on whe different in formants were in substantial agreement where they gave duplicate information al though they did not all know the same. Avunculocal residence, tion, although ther ascertaining the pattern of avunculocal residence, $I$ then went back over the data and asked the informants to comment on the exceptional cases, and also questioned them on the ideal life-cycle. ${ }^{2}$

The social structure of Losap is in many ways similar to that of the island of Romonum in Truk Lagoon, as has been presented by Goodenough in his recent monograph (1951). There are largely the same matrilineal sibs on Losap found elsewhere in Truk District. Subdivisions of these of varying degrees of integration are found. Most of the land is held by corporate matrilineages, although, as in Truk, if a man is the last member of his lineage, his children will inherit his land in preference to distant sibmates (just how distant is a matter of dispute).

Informants said that a close co-operation was maintained between brother and sister. Most of the food for a woman and her children is supplied ideally by her brother, even though this man lives in another house. This is not too difficult for a woman's brother since nearly all the people of the Losap community proper live on a single small islet, a couple of minutes walk away from any other household at the most. A woman's husband, of course, is ideally occupied feeding his sister and his sister's children. Judging from informants statements, this ideal pattern is followed where a group of relatives finds, given the numbers of individuals in the various kin positions, that their property can be effectively exploited within the pattern, although, for reasons to be dis cussed below and as suggested by the high frequency of alternate modes of residence, there are many exceptions in practice.

As a boy grows older and becomes capable of performing useful work, then claims of his lineage on his labor increase, and the boy's mother's brother exercises increasing authority over him. Sometime between puberty and mar-

riage, age varying considerably for the individual, he is likely to move to his mother's brother's house and bring his wife to live there when he marries.

Since the entire population lives in a concentrated village on the small islet of Losap proper, the move of a boy to his mother's brother's house is not such a sharp break for a boy. He can easily visit his parents when he is not working.

Concentrated villages are now found on nearly every island in Truk District, but most of them were established within the memory of living people following the insistence of foreign administrators. It appears that over most of the district each matrilocal extended family originally tended to have its own establishment on lineage land, somewhat removed from other families. But on Losap the village pattern was reportedly indigenous. The very names of the islets suggest this. The large, uninhabited island is named Lee-röl (Laol on charts), literally, "In-(the)-Forest," while Losap, the name of the small inhabited island, appears to mean "At-(the)-Inhabited-Place" (native pronunciation Loo-sópw, presumably from Lee-sópw). This contrast between residential and agricultural areas is not absolute, however. The houses have grounds which are usually large enough to have significant agricultural value, especially in view of the dense population of the atoll (estimated over 1,500 per square mile). Mention has already been made of the frequency of alternative matrilocal and patrilocal modes of residence. Discussion of specific cases with informants revealed that these alternatives are very important in solving problems which would arise from attempting to follow the ideal pattern of avunculocal residence and male matrilineal inheritance of land.

One condition under which matrilocal residence becomes preferable is when all the surviving young adult members of a lineage are female. Normally these women and their children would be supported from the lineage land by the women's brothers. Only the men are felt capable of doing the bulk of the agricultural work on this island, including that connected with both breadfruit and taro, the two principal foods. Moreover, only men are felt capable of pounding poi from these foods. (This, incidentally, is in contrast to the Mortlocks, where women pound poi on everyday occasions and help raise taro.) The women, looking to the future, know that their sons will be able to support them from this land when those sons become of age. The sons will also need the land for themselves and their sisters, so the women are reluctant to call on the help of distant sibmates or other relatives who might be hard to evict later when their own children or nephews needed the land. In these circumstances young women and their guardians encourage matrilocal residence in order to bring in men to work the family land, until the women bear new male heirs.

Just as women who have too few brothers or male lineage mates wish to remain on their own land and bring in their husbands to work it, so in a lineage with too many males men aware of the shortage of lineage land are inspired to look for land from other sources, land of their wives' lineages for one. This again may result in matrilocal residence. 
Under what conditions are couples likely to reside patrilocally? Informants say that some fathers like their sons to stay with them for reasons of personal affection and also to take care of them in their old age. As long as the father's lineage land is not too crowded, the other members of the lineage will not press for the expulsion of the son while the father is still alive, although a man would be expected to leave his father's matrilineage land after his father's death. Moreover, if the father is the last male of his lineage-if he has no sister's sons to care for him and exploit the lineage property - he will want to have his own sons stay in his household and help him with the work on the land. Patrilineal inheritance is automatic if there are no close matrilineal heirs. A man would also find it easier to keep one of his sons if he or his wife's sisters had a large number of sons, more than his wife's brothers could easily employ or support on their matrilineage land.

Thus a man from a crowded lineage may be motivated to use his father's lineage land as well as his wife's lineage land. And, conversely, when a lineage lacks enough young men to work its land, the old men may seek manpower either by encouraging their sons and sons' wives to stay with them in patrilocal residence or by encouraging their daughters' husbands to join the residence group.

The above discussion points out some inherent difficulties in an ideal avunculocal social system. To work according to the ideal pattern, each generation must contain both males and females. A matrilocal extended family will cease if no females are born, but it can have several generations without male births. Likewise a patrilocal extended family can go on indefinitely without female children. But if for even one generation an avunculocal extended family lacks sisters for its men, it will become extinct in the next generation. If it lacks males, the matrilineage may continue but the avunculocal pattern can no longer be maintained. The probability that children of both sexes will be born in a given generation increases with the number of children included in the family group. In a roughly stable population the number of children in the kin group would depend, on the average, on the initial size of the kin group, and this on Losap appears to be fairly small. In any case, since the avunculocal residence pattern requires the birth of children of both sexes in a given generation to be maintained, family groups in a culture idealizing avunculocal residence are twice as likely to fail as those in cultures with matrilocal or patrilocal ideal patterns, where family continuity and stability is possible with the birth of children of only one sex in a given family.

Of course these difficulties of avunculocal residence revealed by logical analysis do not in practice doom concrete residence groups encountering them to certain extinction. The Losap people cope with these situations principally by frankly permitting alternate modes of residence and inheritance. Another device, little used on Losap, would be to extend kinship ties further, as to remote sibmates or to paternal parallel cousins, thus creating substitutes for the missing relatives.

The exact degree to which kinship is extended for purposes of land use and

inheritance is not clearly formulated on Losap, but in practice it tends to be narrow. One of the great causes of land disputes coming to my attention was just this question: if a man has no matrilineal heirs in his immediate lineage, how distant must other matrilineal kinsmen be before the man can ignore them and turn the land over to his own children? Some of the "have-nots" give the answer: any sibmate living on Losap or its tributary island of Pis at the other end of the lagoon should be eligible to inherit the land. But the "haves" in these circumstances tend to want their own children to succeed to the lineage land on their death, even though while alive they might let remote sibmates make copra on the land or otherwise use it in exchange for a share of the products.

The question arises as to why the people of Losap have avunculocal residence, surrounded as they are by culturally related islands with matrilocal residence. Several factors discussed below, as well as theoretical considerations, indicate that avunculocal residence on Losap has evolved locally from a pattern of matrilocal residence originally shared with adjacent cultures.

The existence of a rather concentrated village appears to be a facilitating factor in this particular case. The closeness of residence gives a man a chance to maintain stronger relations with his sister and her children than on other nearby islands, even though on Losap, as on all the islands in Truk District, a man and his sister normally live in separate households. The Losap version of avunculocal residence, where a man living on his matrilineage land provides for his sister, who lives on her husband's matrilineage land, would be much more difficult in a scattered community, and a more dispersed residence pattern seems to have been characteristic of other islands in the area. The concentration also permits parents to retain strong ties with their children of both sexes, even though ideally children cease residence with their parents at marriage. (A woman generally goes to her own matrilineage land if her husband dies before she does. She may then be reunited with her adult sons.)

The concentration of population itself appears to be the result of an effort to take advantage of the previously mentioned peculiar conformation of the atoll for protection from the occasional devastating typhoons. The low islanders in the Central Carolines are usually careful to pick the least exposed areas for dwelling sites, even though this usually means less sea breeze and more mosquitoes

The geography of the tributary island of Pis does not especially favor a concentration of population, although here too the people live in a single village, reputed to be aboriginal. But the oldest settlers on Pis with living descendants are said to have come from Losap. If so, we would expect them to bring the village pattern with them. There are traditions of typhoons missing Losap proper while washing over Pis and killing most of its people, and even washing away completely an adjacent islet. The relative vulnerability of $P$ is to typhoons may be an important factor in explaining its subservience to Losap proper. This vulnerability would certainly constitute a major economic and military handicap from time to time. 
Avunculocal residence is generally supposed to develop out of prior matrilocal residence in response to a strengthening of the status of men (Murdock 1949:207). An examination of the case on Losap reveals data from which a prehistoric strengthening of the status of men may be inferred. It was noted prehistoric strengthening of the status of men may be inferred. It was work of raising, harvesting, and preparing food. This appears to be tied in with a raising, tendency for men on Losap to work their own (matrilineage) lands ran their wives' lands. It is interesting to recall here that the nearby island of Nama was the most strongly matrilocal of all islands on which I island of Nama was the most strongly matrilocal of all islands on which $I$ made a census, and a Nama informant told me, "We like to go live on our
wives' lands, for then we can get food from them and even give some to our parents."

With the Losap men working harder in food production and preparation, the question of course occurred to me: What do the Losap wives do? When I asked informants, they replied that the women sat at home and made mats and other handicrafts. It is true that mats, hats, cigarette cases, etc., purand other han Losap have been of much better quality than chased by American traders from Losap have been of much better quality than those from most other islands in Truk District. The volume of production has also been higher. While some of these articles are of modern design, there is the suggestion here of an especially high skill and interest of the Losap women in handicrafts.

I would suggest that the location of the island is involved in the explanation of this superiority of handicrafts. It is known that in precontact times there was an extensive trade between the high islands of Truk Lagoon and there was an extensive trade between the high islands of Truk tow islanders brought in pandanus mats, the surround coral beads, etc., and took back principally turmeric and woven lavalavas, redcora the closest supplemental food. Of all the low islands, Losap and Nama are the closest to Truk proper. It seems reasonable to assume that their trade with Truk was especially important, in view of their considerable advantage over the other low islands in closeness to market.

Food imported from Truk as a supplement to locally produced food could be of more importance to close islands such as Losap and Nama than to farther islands such as the Mortlocks, Namonuito, Puluwat, etc. The crew could af ford to load their canoes more heavily on such a short trip, and they would not ford to load their canoes more heavily on such a short trip, and they would or need to consume as much in transit themselves. Also, in times of famine or hardship on the low islands, the men could more easily transport their female relatives and children to the comparative abundance of Truk, to stay with trading partners and distant sibmates there until times improved again. Traditions exist on Losap of famines when most of the population migrated to Truk for short periods and later returned to their original homes.

I suspect that over a long period Losap and Nama have been able to maintain a greater population density than the other low islands because of readier access to high island foods in time of local shortage and famine. The readier access to high island foods in tima Navy Deofficially reported population density of Losap Atoll and Nama (Navy Department 1949:iii), 1,807 and 1,810 respectively, is nearly three times the average population density of the Mortlocks, the most comparable islands in

culture, history, and geography. This population difference is partly due to a typhoon early this century which caused many deaths in the Mortlocks and much emigration, but one also suspects that the aboriginal population densities may have been higher on Losap and Nama, though probably not so much so.

Since Losap was, so to speak, almost "within commuting distance" of Truk, little knowledge of navigation was required to make the trip. On some of the farther low islands (even up to today on Puluwat) the men have traditionally come into Truk in great expeditions of a number of canoes, all under the leadership of a single master navigator (palï, pönii). It is my impression that on Losap, however, little knowledge was felt necessary for a trip to Truk, and that expeditions of one or two canoes were common. A number of such small expeditions could carry even a greater volume of trade than the rarer mass expeditions of the farther low islands. At the same time, there would be no need for the sudden removal of a large portion of the male population, as is characteristic of the mass expeditions. Enough men could always remain on Losap to take care of the heavier male domestic duties there, while on the farther islands the women were forced to share in these in the periodic absence of so many men.

In view of the advantageous location of Losap for trade one would expect that the men would encourage the women to exert themselves producing handicrafts for export to Truk, and that the men themselves would take on more of the work of producing and preparing food to give the women more time to produce trade goods. At the same time, men's control of navigation and trade would bolster their status.

The status of men on Losap may have been further strengthened by a political structure which was more integrated than that of the Mortlocks. While both missionary influence and foreign rule have apparently altered the political structure of the island in the last seventy years, it appears that Losap and Pis within Losap Atoll and the nearby island of Nama constituted a political unit aboriginally; also that the chief of the highest of the three traditional original sibs of Losap (Luukenfönü, Söor, Maasaalö-these constituted a sort of aristocracy) was also the paramount chief of the three island communities. In the Mortlocks, however, each inhabited island appears to have been independent of the rest, not to speak of such a thing as lasting political subjugation of an island not in the same lagoon.

Certain evidence as to the current status of men and women on Losap aside from that already mentioned also suggests that the men have a somewhat higher status there than on other nearby islands. Although Losap was converted to Christianity later than a number of other islands in Truk District, an unusually large proportion of the native Protestant ministers in the district at present are natives of Losap. Apparently the missionaries also sensed a self-confidence and initiative in the Losap men which they did not find in the same degree in men of other islands. Such personal qualities, of course, are suggestive of a higher status of men. ${ }^{3}$

In summary, available contemporary evidence supports the hypothesis 
that prehistoric economic and political factors, perhaps ultimately referable to geography and topography, favored a heightening of the status of men on Losap and that following this, the people, over time, shifted from an original matrilocal residence to one of preferred avunculocal pattern of preferred matrilocal residence to development of residence, which they continue to retain at present. The development of avunculocal residence and related customs as practiced on Losap appears to have been facilitated by a concentration of the population in a village, in contrast to a general pattern of dispersed residence which seems to have been typical aboriginally on other islands in the general area. Both patrilocal and matrilocal residence occur with moderately great frequency as alternate patterns, and these serve as solutions to inherent difficulties in the practical application of the ideal of avunculocal residence.

\section{NOTES}

The Navy-sponsored Coordinated 1 This surver Investigation of Micronesian Anthropology (CrMA), conducted shortly after Wont War in one thing, at the time I held the position of Anthropological Field Consultant with the naval Civil Administration Unit at Truk. This and similar positions in the Trust Territory were established as a consequence of the usefulness of the CIMA data to the administration and had as their object increasing the amount of reliable information on the native cultures avallable to American fficials in the field. Second, the residence census was part of a general extensive study of land oficials in the field. Second, the other islands in the district tenure throughout Truk District to dete island of Romonum in Truk Lagoon, studied intensively were similar in certain key respects to the island of Romo was also director of the CIMA program by the Yale CIMA team under Dr. G. P. Murdock, who was also director of the CIMA prested in Goodas a whole. The information on land tenure gathered by the Yale team is presented in Good enough's notable monograph (1951). My own supplemental study was a report to the administration, as yet unpublished.

2 On a numer of other occasions during my employment in the Trust Territory in the years (o tosap itself and while they were visitin

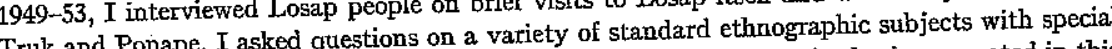
Truk and Ponape. I asked questions on a variety of standard ethnographic subjects with spectis emphasis paper.

${ }^{3}$ Gladwin and Sarason's findings on natives of the matrilocal island of Romonum in Truk . Their Lagoon indicate a relate pith the findings and interpretation here.

\section{REFERENCES CITED}

GTADWN, T. and S. B. SARASON

1953 Truk: man in paradise. Viking Fund Publications in Anthropology, No. 20. New York.

GOODENOUGH, WARD H.

1951 Property, kin, and community on Truk. Yale University Publications in Anthropology, No. 46. New Haven.

Murdock, George PeTer

1949 Social structure. New York, Macmillan.

NaVy DEPARTMENT

1949 Report on the administration of the Trust Territory of the Pacific Islands. Washing ton, D. C.
Bernard Mishkin, I9I $3^{-1954}$

BERNARD MISHKIN died suddenly of a heart attack in Frankfort on the Main, Germany, on July 13, 1954. He was but 41 years of age. Mishkin was not widely known in the field of anthropology, but a large group of anthropologists knew him as a man of real brilliance and of great promise who wavered between an academic-intellectual and a public administratorbusiness career. An example of his potentiality as an anthropologist is his brilliant monograph, Rank and Warfare among the Plains Indians, in which, with carefully collected field data from the Kiowa, he corrected the view of Plains warfare as a "game" and showed it in its stark relationship to economic gain and social status differentiation. But, like many other anthropologists of his generation, he was diverted into military service, administrative activities, and finally into business. When he died he was an executive of the Flying Tigers, engaged in transporting students to and from Europe, Europeans to the United States, and people to Israel by air. Despite his varied activities, Mishkin was devoted to anthropology as a science, and he always thought of himself, even when occupied in another field, as an anthropologist. He kept himself abreast of recent developments in ethnology and social anthropology. At his death, anthropology lost a vivid personality, a highly provocative mind, and potentially a scholar of considerable theoretical contribution.

Mishkin was born in Theodhosia, Crimea, on January 19, 1913, and when he was two years old his parents brought him to the United States where he attended both primary and secondary schools. He early showed his scholarly abilities. In 1933, he received his B.A. degree from Franklin and Marshall College. The next year he received an M.A. degree in psychology from Columbia University, and in 1937 he was granted the Ph.D. degree in anthropology from Columbia when he was but 24 years of age. At Columbia University, his abilities were early recognized by Franz Boas and Ruth Benedict, with whom he studied. Furthermore, during these same years he also had an active research career. During the summer of 1935 he was a Fellow of the Santa $\mathrm{Fe}$ Laboratory of Anthropology, doing the field work with the Kiowa of Oklahoma which later resulted in his monograph and doctoral dissertation. In 1936, he received a fellowship from the Social Science Research Council, on which he traveled to New Guinea where he did field work in the Wapi area.

After receiving his doctoral degree he began his research in South America, an area which became, in a sense, his field of major interest. In 1937 he carried out field work in Kauri, an Indian village in highland Peru, under the auspices of the Columbia University Council for Research in the Social Sciences. In 1941 he returned to Peru as Visiting Curator at the National Museum of Peru, on a grant from the Committee on Inter-American Artistic and Intellectual Cooperation. He had a particularly effective influence upon the development of ethnology in Peruvian universities and museums. Again in 1948 he traveled to South America, this time as a consultant to UNESCO. In this 